\title{
Reciprocal Predictive Relationships between Amyloid and Tau Biomarkers in Alzheimer's Disease Progression: An Empirical Model
}

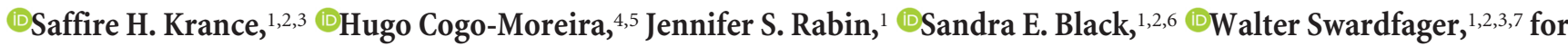 \\ the Alzheimer's Disease Neuroimaging Initiative* \\ ${ }^{1}$ Hurvitz Brain Sciences Program, ${ }^{2}$ LC Campbell Cognitive Neurology Unit, Sunnybrook Research Institute, Toronto M4N 3M5, Canada, ${ }^{3}$ Department of \\ Pharmacology and Toxicology, University of Toronto, Toronto M5S 1A8, Canada, ${ }^{4}$ Freie Universität Berlin, 14195 Berlin, Germany, ${ }^{5}$ Departamento de \\ Psiquiatria, Universidade Federal de São Paulo, São Paulo, Brazil, 04017-030, 6Department of Medicine (Neurology Division), University of Toronto, \\ Toronto M5G 2C4, Canada, and 7University Health Network Toronto Rehabilitation Institute, Toronto M4G 1R7, Canada
}

There is an urgent need to understand the relationships between amyloid- $\beta(\mathrm{A} \beta)$ and tau in the progression of Alzheimer's disease to identify treatment targets. Here we examine reciprocal predictions of brain $\mathrm{A} \beta$ burden quantified by positron emission tomography and CSF concentrations of $A \beta 42$ and phosphorylated tau (p-tau). Each biomarker was examined over 48 months in two separate cross-lagged models; one in asymptomatic healthy elderly people (men and women), and one in patients with Alzheimer's disease (AD) dementia or mild cognitive impairment (MCI). The models examine predictions of each biomarker on the progression of the others, considering each previous and concurrent measure. In healthy elderly, lower CSF A $\beta 42$ predicted $\mathrm{A} \beta$ deposition and reciprocally, $\mathrm{A} \beta$ burden predicted a decrease in CSF $A \beta 42$. Lower CSF A $\beta 42$ predicted an increase in CSF $p$-tau, and CSF $p$-tau predicted A $\beta$ deposition. In AD/MCI, lower CSF $\mathrm{A} \beta 42$ predicted $\mathrm{A} \beta$ deposition and $\mathrm{A} \beta$ burden reciprocally predicted CSF $\mathrm{A} \beta 42$ changes; however, in contrast to healthy elderly, CSF p-tau concentrations did not predict A $\beta$ biomarkers, or vice versa. In post hoc models examining cognitive status, CSF A $\beta 42$ predicted Mini Mental State Examination (MMSE) scores in healthy elderly, whereas A $\beta$ burden and CSF p-tau predicted MMSE scores in AD/MCI. The findings describe reciprocal predictions between $\mathrm{A} \beta$ and tau biomarkers in healthy elderly and they implicate mechanisms underlying low CSF A $\beta 42$ in Alzheimer's disease pathogenesis and progression. In symptomatic Alzheimer's disease, CSF A $\beta 42$ and A $\beta$ deposition predicted each other; however, $\mathrm{A} \beta$ and CSF $\mathrm{p}$-tau progressed independently and they independently predicted cognitive decline.

Key words: amyloid; biomarkers; CSF; PET; tau

\section{Significance Statement}

This study offers empirical evidence concerning the hypothesized "amyloid cascade", as it progressed over 4 years in healthy elderly people and in Alzheimer's disease patients. In healthy elderly, CSF amyloid changes predicted amyloid deposition, CSF phosphorylated tau concentrations, and a decline in cognitive status. Phosphorylated tau concentrations specifically predicted amyloid deposition. In Alzheimer's disease patients, although amyloid deposition and CSF amyloid changes continued to "cascade", there was no evidence to suggest that amyloid and tau biomarkers predicted each other, although both amyloid deposition and CSF tau progression predicted cognitive decline independently. Taking advantage of repeated amyloid PET and CSF measures, this dynamic view offers new insight into the progression of Alzheimer's disease biomarkers and their relationships with cognitive decline.

\section{Introduction}

Alzheimer's disease $(\mathrm{AD})$ is defined by two pathological hallmarks: $A \beta$ plaques and neurofibrillary tangles (NFTs), caused, respectively, by extracellular aggregation of $\mathrm{A} \beta$ and intracellular

Received May 3, 2019; revised July 1, 2019; accepted July 19, 2019.

Author contributions: S.H.K., H.C.-M., J.S.R., S.E.B., and W.S. designed research; S.H.K. performed research; S.H.K., H.C.-M., and W.S. analyzed data; S.H.K. and W.S. wrote the paper; H.C.-M., J.S.R., and S.E.B. critically revised the manuscript. hyperphosphorylation of tau (Ittner and Götz, 2011). A longstanding amyloid hypothesis implicates $A \beta$ as the initiator and

This work was supported by the Alzheimer's Association (U.S.) and Brain Canada (AARG501466). H.C.-M. is thankful to CAPES/Alexander von Humboldt Foundation for the Experienced Researcher Postdoctoral Fellowship (88881.145593/2017-01). S.H.K., W.S. and S.E.B. acknowledge support from the Heart and Stroke Foundation Canadian Partnership for Stroke Recovery. J.S.R. acknowledges support from the Harquail Centre for Neuromodulation. Data collection and sharing for this project was funded by the Alzheimer's Disease Neuroimaging Initiative (ADNI; National Institutes of Health Grant U01 AG024904) and DOD ADNI (Department of Defense award W81XWH12-2-0012). ADNI is funded by the National Institute on Aging, the National Institute of Biomedical Imaging and 
driver of AD pathological progression (Hardy and Selkoe, 2002; Karran et al., 2011), although some have speculated that $\mathrm{A} \beta$ and tau pathologies may be driven by a common upstream pathological process (Small and Duff, 2008). The failure of several antiamyloid therapies to improve clinical symptoms in $\mathrm{AD}$ dementia (Castello et al., 2014) highlights an urgency to understand the interactions between $\mathrm{A} \beta$ and tau, and their roles in $\mathrm{AD}$ progression.

Genetic evidence supports an initiatory role of $\mathrm{A} \beta$ dysregulation in $\mathrm{AD}$; mutations in the amyloid precursor protein $(A P P)$ gene (Goate et al., 1991), as well as presenilin 1 (Sherrington et al., 1995) and 2 (Levy-Lahad et al., 1995), can cause autosomal dominantly inherited $\mathrm{AD}$, whereas the roles of polymorphisms that increase the likelihood of late-onset $\mathrm{AD}$ remain incompletely understood. Tau mutations can cause frontotemporal dementia (Hutton et al., 1998), but not AD, implicating tau as a downstream effect of $\mathrm{A} \beta$, common across several dementia syndromes (Karran et al., 2011).

The temporal evolution of AD biomarkers shows a characteristic decrease in CSF $\mathrm{A} \beta$ peptide $42(\mathrm{~A} \beta 42)$ concentrations, and a subsequent increase in $A \beta$ deposition inferred from positron emission tomography (PET) scans, that precedes increases in CSF tau concentrations or tau deposition in most brain regions (Jack et al., 2013; Blennow et al., 2015). Some evidence opposes this canonical sequence of biomarker staging. Braak and Braak (1997) reported that tau pathology typically appeared at younger ages than $\mathrm{A} \beta$ pathology. Examining both amyloid and tau PET, Cho et al. (2018) found that tau deposition often appears in the temporal cortex, but not more broadly throughout other cortical areas, in the absence of detectable neocortical A $\beta$. Those findings would be consistent with the suggestion that the predominant role of A $\beta$ may be to exacerbate tau pathology (Jack et al., 2013; Stancu et al., 2014).

To date, most biomarker studies have been adynamic, and so an amyloid "cascade" per se, involving reciprocal synergy between $\mathrm{A} \beta$ and tau progression, has yet to be empirically proven in living people. Moreover, existing clinical evidence fails to identify a role of $\mathrm{A} \beta$ beyond the initiation of $\mathrm{AD}$ pathogenesis, and the nature of its relationship with tau progression has been described only recently as $\mathrm{AD}$ symptoms develop and progress (Hanseeuw et al., 2019; Sperling et al., 2019). Possibly due in part to a previous lack of long-term clinical data, the $\mathrm{AD}$ cascade has remained an enigmatic target for treatment.

Bioengineering, and through generous contributions from the following: AbbVie, Alzheimer's Association, Alzheimer's Drug Discovery Foundation, Araclon Biotech, BioClinica, Biogen, Bristol-Myers Squibb, CereSpir, Cogstate, Eisai, Elan Pharmaceuticals, Eli Lilly, EUROIMMUN, F. Hoffmann-La Roche and its affiliated company Genentech, Fujirebio, GE Healthcare, IXICO, Janssen Alzheimer Immunotherapy Research \& Development, Johnson \& Johnson Pharmaceutical Research \& Development, Lumosity, Lundbeck, Merck, Meso Scale Diagnostics, NeuroRx Research, Neurotrack Technologies, Novartis Pharmaceuticals, Pfizer, Piramal Imaging, Servier, Takeda Pharmaceutical, and Transition Therapeutics. The Canadian Institutes of Health Research supported ADNI clinical sites in Canada. Private sector contributions are facilitated by the Foundation for the National Institutes of Health (http://www.fnih.org). The grantee organization is the Northern California Institute for Research and Education, and the study is coordinated by the Alzheimer's Therapeutic Research Institute at the University of Southern California. ADNI data are disseminated by the Laboratory for Neuro Imaging at the University of Southern California. We thank Dr. Ellen Hamaker for her communications about CLPM design.

S.E.B. reports ad-hoc consultancies for Novartis, Merck, Eli Lilly, and Pfizer; CME: Medscape/Biogen, Eli Lilly, Novartis; and Grants to institution from Eli Lilly, GE Healthcare, Biogen Idec, Novartis, Genentech, and Optina. The remaining authors declare no competing financial interests.

*Data used in preparation of this paper were obtained from the ADNI database (http://adni.loni.usc.edu). As such, the investigators within the ADNI contributed to the design and implementation of ADNI and/or provided data but did not participate in analysis or writing of the paper. A complete listing of ADNI investigators can be found at: http://adni.loni.usc.edu/wp-content/uploads/how_to_apply/ADNI_Acknowledgement_List.pdf.

Correspondence should be addressed to Walter Swardfager at w.swardfager@utoronto.ca.

https://doi.org/10.1523/JNEUROSCl.1056-19.2019

Copyright $\odot 2019$ the authors
The present study takes advantage of repeated measurements collected by the Alzheimer's Disease Neuroimaging Initiative (ADNI) investigators to examine the dynamic interplay between biomarkers of $\mathrm{A} \beta$ and tau in their progression over 48 months, both in asymptomatic healthy elderly controls (HCs) and in cognitively impaired individuals with $\mathrm{AD}$ dementia or mild cognitive impairment (MCI) who have biomarker confirmation of amyloid positivity $(\mathrm{AD} / \mathrm{MCI})$. The predictive relationships between CSF concentrations of $\mathrm{A} \beta 42$, CSF concentrations of tau phosphorylated at threonine 181 ( $\mathrm{p}$-tau), and levels of $\mathrm{A} \beta$ deposition obtained from ${ }^{18} \mathrm{~F}$-florbetapir $\left({ }^{18} \mathrm{~F}-\mathrm{AV}\right.$-45) PET (Johnson et al., 2013) are examined using a cross-lagged panel model (CLPM), which offers an ideal statistical environment to dissect reciprocal predictive relationships between co-propagating factors over time. Specifically, a model was constructed to examine (1) the predictive relationships between CSF A $\beta 42$ and CSF p-tau progression; (2) the predictive relationship between amyloid deposition and the progression of CSF A $\beta 42$ and CSF p-tau, and the converse predictions of CSF A $\beta 42$ and CSF p-tau on amyloid deposition; and (3) amyloid and tau progression in $\mathrm{HC}$ and AD/ MCI separately to specify their relationships in asymptomatic and symptomatic people. Post hoc models were constructed including Mini-Mental State Examination (MMSE) scores to explore the predictive relationships between these biomarkers and changes in cognitive status.

\section{Materials and Methods}

Sample. Separate analyses were conducted in HC and AD/MCI participants (http://adni.loni.usc.edu/) to examine the predictive relationships between $\mathrm{A} \beta$ and tau biomarkers in asymptomatic elderly and in cognitively impaired biomarker-confirmed symptomatic people. Data were used from ADNI GO and 2 because ${ }^{18} \mathrm{~F}-\mathrm{AV}-45$ PET scans on subjects began in these study phases. ADNI was launched in 2003, as a publicprivate partnership, with the primary goal of determining whether neuroimaging, other biomarkers, and clinical and neuropsychological assessments could be combined to measure the progression of MCI and early AD. ADNI was conducted according to Good Clinical Practice guidelines, US 21CFR Part 50-Protection of Human Subjects, and Part 56-Institutional Review Boards, and pursuant to state and federal regulations. Written informed consent and HIPAA authorizations for the study were obtained from all participants and/or authorized representatives and the study partners.

Measures. CSF p-tau concentrations, CSF A $\beta 42$ concentrations, and $\mathrm{A} \beta$ deposition were included at each of the three waves (baseline, 24 months, 48 months) in the model. Two biomarkers of A $\beta$ pathology were included because AD-related abnormalities in these biomarkers are thought to initiate at temporally distinct points in $\mathrm{AD}$ pathogenesis (Jack et al., 2013), and reflect changes in different forms of $A \beta$ (soluble versus fibrillar). Longitudinal CSF p-tau concentrations were chosen over total tau (t-tau) concentrations to represent progression of tauopathy; although both t-tau and p-tau behave similarly in AD progression (Fagan et al., 2009), and both are associated with NFT burden on autopsy (Tapiola et al., 2009), p-tau has been shown to have greater specificity for AD than t-tau (Schraen-Maschke et al., 2008). Five potential confounders were introduced as covariates: baseline age, baseline MMSE score, baseline whole-brain atrophy, sex, and APOE $\varepsilon 4$ allele presence/absence.

Fully automated Roche Elecsys immunoassays were used to quantify CSF concentrations of all $\mathrm{AD}$ biomarkers. $\mathrm{A} \beta$ deposition values were obtained from ${ }^{18} \mathrm{~F}-\mathrm{AV}-45$ cortical summary measures (SUVR) normalized by a composite reference region (made up of whole cerebellum, brainstem/pons, and eroded subcortical white matter), as white mattercontaining reference regions have been shown to produce greater accuracy in longitudinal ${ }^{18} \mathrm{~F}-\mathrm{AV}-45$ measures (Landau et al., 2015). As the PET signal was normalized to a composite reference region, the recommended cutoff value for amyloid positivity was 0.79 ; all $\mathrm{AD} / \mathrm{MCI}$ subjects with normalized SUVR values above the cutoff at their baseline visit were 


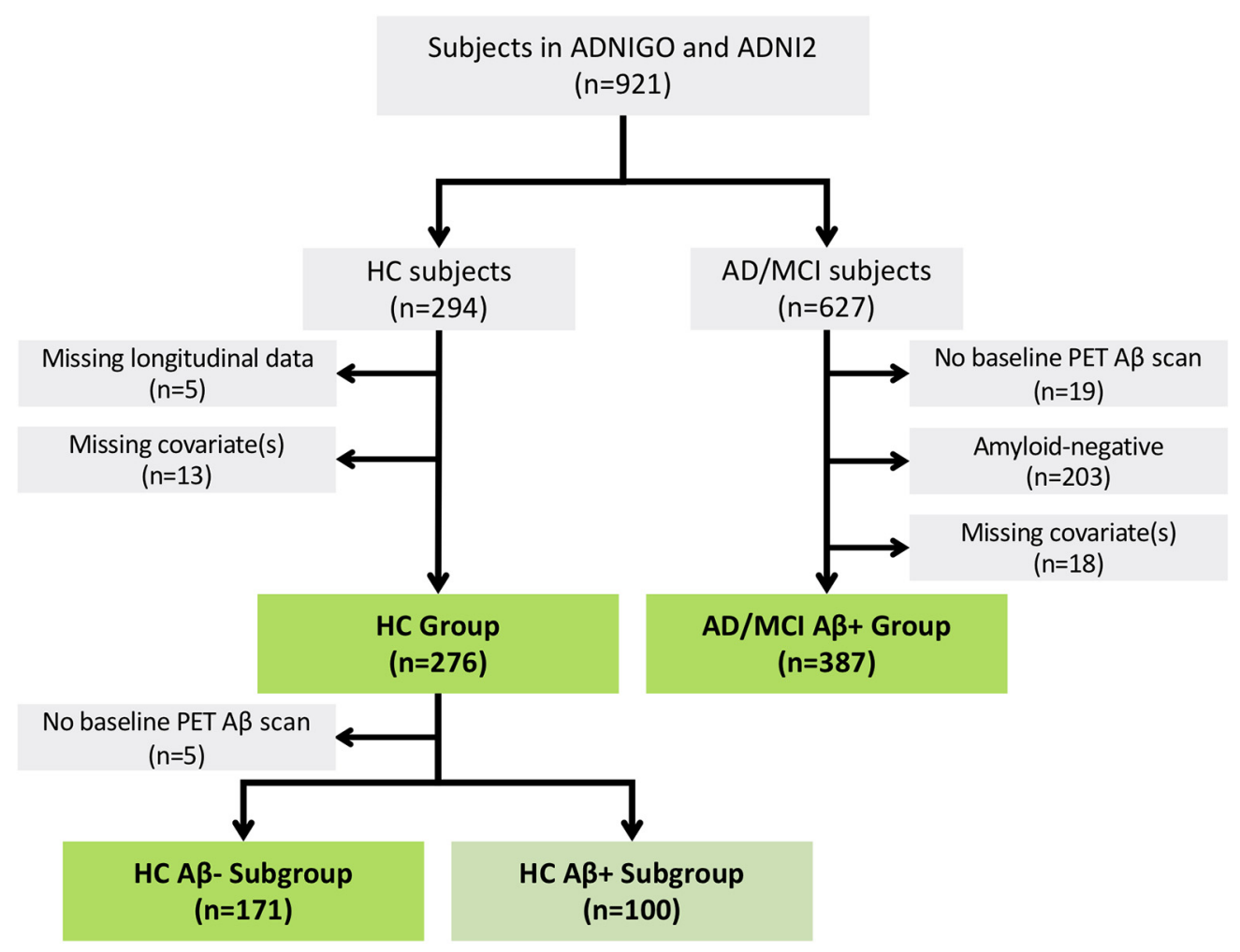

Figure 1. Flow diagram of determination of included subjects in $\mathrm{HC}$ and $\mathrm{AD} / \mathrm{MCl}$ study groups. All $\mathrm{AD} / \mathrm{MCl}$ were PET-confirmed $\mathrm{A} \beta+$ (above the amyloid positivity cutoff); $\mathrm{HC}$ were separated into $A \beta+$ and $A \beta-$ subgroups for further analyses. Groups and subgroups investigated in green.

included in the $\mathrm{AD} / \mathrm{MCI} \mathrm{A} \beta+$ group, whereas all $\mathrm{HC}$ subjects were included regardless of amyloid status. Analyses were performed separately in a subgroup of $\mathrm{HC}$ subjects with baseline SUVR values below the cutoff (HC A $\beta-$ ), and in a subgroup of HC subjects above the SUVR cutoff $(\mathrm{HC} \mathrm{A} \beta+)$. For magnetic resonance imaging data used to calculate whole-brain atrophy, 3T scans were processed with FreeSurfer 5.1. All data used for analyses were downloaded from the ADNI database in January 2019. Whole-brain atrophy was estimated by dividing the total brain parenchymal volume by intracranial volume.

Experimental design and statistical analysis. The CLPM is a statistical technique used to understand the most likely predictive relationships between variables over time (Kenny and Harackiewicz, 1979; Hamaker et al., 2015). The CLPM tests predictions of each measure on the progression of the others, considering (1) each previous measure, (2) each concurrent measure, and (3) any relevant covariates (Karran et al., 2011). Unlike univariate mediation/predictive models, the CLPM does not assume a particular order in which variables influence each other, and unlike data-driven or descriptive approaches, the CLPM, via fit indices, tests a hypothesis about how well the data fit a specific model structure that is defined a priori (Kenny and Harackiewicz, 1979; Hamaker et al., 2015). Analyses were conducted in Mplus v8, using three waves of longitudinal data (baseline, 24 months, 48 months), as both CSF and PET data were available at those time points and they are sufficiently distanced in time to detect meaningful changes in each biomarker. A robust maximum likelihood estimator was used, allowing for inclusion of participants despite missing data without imputation under the assumption of a missing at random mechanism. Standardized coefficients $(\beta)$ and their significance values were estimated for each association tested.

The CLPM approach created nine grand mean centered variables (see Fig. 2A, $B$, larger circles) from each of three observed variables across three waves (see Fig. $2 A, B$, rectangles) as described previously (Hamaker et al., 2015). Briefly, these variables were predicted by their own antecedent measures in an autoregressive manner, and also by each of the other measures at the antecedent time point (i.e., "cross-lagged"). These effects were estimated freely. The residuals at each wave (latent variables represented by small circles) were allowed to be correlated with each other to account for time-specific correlations between the biomarkers. Goodness of fit was assessed for all models using: root mean square error of approximation (RMSEA), comparative fit index (CFI), Tucker-Lewis index (TLI), and standardized root mean square residual (SRMR). Good fit was indicated for values of RMSEA $<0.06$, CFI $>0.95$, TLI $>0.90$, and SRMR $<0.08$.

Because of similarities in CSF p-tau and t-tau measures as AD biomarkers, post hoc analyses substituting longitudinal CSF t-tau for p-tau were conducted. To explore relationships between the biomarkers and changes in cognitive status over time, MMSE scores from each of the three waves were considered as a fourth cross-lagged variable (instead of as a covariate) in a second set of post hoc models.

\section{Results \\ Sample}

There were 921 subjects in ADNI GO and ADNI 2. Of these subjects, 294 were defined clinically as healthy controls, and 405 were amyloid-positive and defined clinically as having either dementia or MCI. From these groups, five subjects were excluded due to missing data at every time point for each longitudinal variable, and 31 subjects were excluded because of missing data on at least one covariate since the analytical framework required no missing data in any predictor. In two instances, the p-tau measurement at a single time point was below the detectable level of the immunoassay, so data were imputed at the sensitivity of the assay. Therefore, $276 \mathrm{HC}$ and $387 \mathrm{AD} / \mathrm{MCI}$ subjects were included in analyses (Fig. 1). Characteristics of participants in both groups can be found in Table 1 .

\section{Testing the models}

The data fit the models well for both HC $($ RMSEA $=0.038, \mathrm{CFI}=$ $0.992, \mathrm{TLI}=0.984, \mathrm{SRMR}=0.020)$ and $\mathrm{AD} / \mathrm{MCI}(\mathrm{RMSEA}=$ $0.046, \mathrm{CFI}=0.983, \mathrm{TLI}=0.965, \mathrm{SRMR}=0.051)$ groups. The data fit the model well for the HC $\mathrm{A} \beta$ - subgroup (RMSEA = 
Table 1. Characteristics of $\mathrm{HC}$ and $\mathrm{AD} / \mathrm{MCl}$ subjects

\begin{tabular}{|c|c|c|}
\hline Characteristic & $\mathrm{HC}(n=276)$ & $\begin{array}{l}\mathrm{AD} / \mathrm{MCl}(n=387) \\
\left(n_{\mathrm{AD}}=119 ; n_{\mathrm{MCl}}=268\right.\end{array}$ \\
\hline Age, mean (SD) & $73(6)$ & $73(7)$ \\
\hline Baseline MMSE, mean (SD) & $29(1)$ & $26(3)$ \\
\hline №. (\%) APOE 44 carriers & $82(30)$ & $266(69)$ \\
\hline No. (\%) male & $128(46)$ & $215(56)$ \\
\hline $\begin{array}{l}\text { No. with CSF A } \beta 42 \text { data (baseline, } \\
24 \text { months, } 48 \text { months) }\end{array}$ & $242,126,37$ & $357,137,40$ \\
\hline $\begin{array}{l}\text { No. with CSF p-tau data; baseline, } \\
24 \text { months, } 48 \text { months }\end{array}$ & $242,126,37$ & $357,137,40$ \\
\hline $\begin{array}{l}\text { No. with 18F-AV-45 PET data; baseline, } \\
24 \text { months, } 48 \text { months) }\end{array}$ & $271,207,129$ & $387,195,86$ \\
\hline $\begin{array}{l}\text { No. amyloid positive/no. amyloid } \\
\text { negative at baseline* }\end{array}$ & $100 / 171$ & 387 \\
\hline
\end{tabular}

$\mathrm{AD} / \mathrm{MCl}$ subjects were PET-confirmed to be above the amyloid positivity cutoff.

*271 of 276 HC subjects had baseline amyloid PET scans, 100 of whom were amyloid-positive.

$0.049, \mathrm{CFI}=0.980, \mathrm{TLI}=0.958, \mathrm{SRMR}=0.061)$, but covariance coverage was insufficient to test a model for the $\mathrm{HC} \mathrm{A} \beta+$ subgroup due to small sample size. For all significant predictions, $\beta$ and $p$ values are shown in Figures 2, $A$ and $B$, and 3 .

\section{Covariate effects, biomarker stability, cross-sectional} correlations, and model residuals

In both $\mathrm{HC}$ and $\mathrm{AD} / \mathrm{MCI}$ groups (Fig. $2 A, B$ ), women had a higher baseline $\mathrm{A} \beta$ burden, and in the $\mathrm{AD} / \mathrm{MCI}$ group, women also had higher baseline CSF p-tau concentrations and higher baseline CSF A $\beta 42$ concentrations. Older subjects in both $\mathrm{HC}$ and $\mathrm{AD} / \mathrm{MCI}$ groups had lower CSF A $\beta 42$ concentrations, and older subjects in the HC group also had higher baseline CSF p-tau concentrations and greater $\mathrm{A} \beta$ burden. APOE $\varepsilon 4$ carriers in both $\mathrm{HC}$ and $\mathrm{AD} / \mathrm{MCI}$ groups had higher baseline $\mathrm{A} \beta$ burden and lower baseline CSF A $\beta 42$ concentrations, and the in $\mathrm{HC}$ group $\mathrm{APOE} \varepsilon 4$ carriers also had higher baseline CSF p-tau concentrations. In the AD/MCI group, baseline MMSE scores and wholebrain atrophy were associated with baseline biomarkers; lower MMSE scores were associated with higher baseline $\mathrm{A} \beta$ burden, higher CSF p-tau concentrations, and lower CSF A $\beta 42$ concentrations, and those with greater baseline atrophy had higher baseline $\mathrm{A} \beta$ burden and lower baseline CSF $\mathrm{A} \beta 42$ concentrations.

CSF A $\beta 42$ concentrations, CSF p-tau concentrations, and A $\beta$ burden each displayed strong longitudinal stability (i.e., each measure strongly predicted its own measure at subsequent time points; Fig. 2A, $B$ ).

Cross-sectional correlations between cross-lagged variables are identified in the covariance and correlation matrices for $\mathrm{HC}$ (Fig. 2-1, available at https://doi.org/10.1523/JNEUROSCI.105619.2019.f2-1, and Fig. 2-2, available at https://doi.org/10.1523/ JNEUROSCI.1056-19.2019.f2-2), for AD/MCI (Fig. 2-3, available at https://doi.org/10.1523/JNEUROSCI.1056-19.2019.f2-3, and Fig. 2-4, available at https://doi.org/10.1523/JNEUROSCI. 1056-19.2019.f2-4), and for the HC A $\beta$ - subgroup (Fig. 3-1, available at https://doi.org/10.1523/JNEUROSCI.1056-19.2019.f3-1, and Fig. 3-2, available at https://doi.org/10.1523/JNEUROSCI.105619.2019.f3-2); they are summarized in Table 2. In both models, CSF $\mathrm{A} \beta 42$ and CSF p-tau residuals were positively correlated, CSF and PET A $\beta$ residuals were negatively correlated, and CSF p-tau concentrations and PET A $\beta$ residuals were positively correlated at various times (Fig. 2A,B).

\section{Cascade characteristics in asymptomatic elderly}

In $\mathrm{HC}$ (Fig. $2 A$ ), lower CSF A $\beta 42$ concentrations consistently predicted the progression of $\mathrm{A} \beta$ deposition and reciprocally $\mathrm{A} \beta$ deposition at baseline predicted a subsequent drop in CSF A $\beta 42$ concentrations between baseline and Month 24. Lower CSF $\mathrm{A} \beta 42$ concentrations at baseline also predicted an increase in CSF p-tau concentrations 24 months later. Higher CSF p-tau concentrations at baseline predicted higher $\mathrm{A} \beta$ burden at Month 24. CSF p-tau concentrations did not predict CSF A $\beta 42$ concentration changes.

In the subgroup of HCs who were PET A $\beta-$, the same predictive relationships were observed, except that $\mathrm{A} \beta$ deposition did not predict CSF A $\beta 42$ concentration changes, but instead, it predicted changes in CSF p-tau concentrations (Fig. 3).

\section{Cascade characteristics in $\mathrm{AD} / \mathrm{MCI}$ subjects}

In $\mathrm{AD} / \mathrm{MCI}$ (Fig. $2 B$ ), lower CSF $\mathrm{A} \beta 42$ concentrations consistently predicted increases in $\mathrm{A} \beta$ deposition across time points, as observed also in $\mathrm{HC}$ subjects and the reciprocal predictive effect was also observed; higher $\mathrm{A} \beta$ burden at Month 24 predicted a decrease in CSF A $\beta 42$ concentrations 24 months later. Neither $\mathrm{A} \beta$ biomarker predicted changes in CSF $\mathrm{p}$-tau concentrations, and CSF $p$-tau concentration changes did not significantly predict changes in either $\mathrm{A} \beta$ biomarker. Results in healthy elderly and $\mathrm{AD} / \mathrm{MCI}$ groups are summarized in Table 2.

\section{Post hoc analyses}

Total tau versus p-tau

Post hoc analyses substituting t-tau for $\mathrm{p}$-tau produced identical significant longitudinal predictions and residual correlations in the AD/MCI model (data not shown). Results were identical in the HC model, except the residual of PET and CSF A $\beta$ biomarkers were no longer correlated at month 24 , and instead the residuals of CSF A $\beta 42$ and p-tau were correlated at month 48 (data not shown).

\section{Progression of cognitive status}

Post hoc models were tested with MMSE scores included as longitudinal variables instead of as a covariate, to discern which biomarkers predicted changes in cognitive status in $\mathrm{HC}$ and $\mathrm{AD} / \mathrm{MCI}$ groups. The models returned good fit indices for $\mathrm{HC}$ $(\mathrm{RMSEA}=0.048, \mathrm{CFI}=0.986, \mathrm{TLI}=0.966, \mathrm{SRMR}=0.044)$ and for $\mathrm{AD} / \mathrm{MCI}$ (RMSEA $=0.056, \mathrm{CFI}=0.975$, TLI $=0.940$, $\mathrm{SRMR}=0.053)$ groups. In both models, all covariate relationships, longitudinal predictions, cross-sectional correlations and residual correlations between biomarkers were unchanged from the previous set of models and additionally, in the AD/MCI group, APOE 4 predicted higher baseline CSF p-tau, and $\mathrm{A} \beta$ burden and CSF p-tau concentration at month 48 were correlated (Fig. $2 A, B$ ). In the $\mathrm{HC}$ group, lower baseline CSF A $\beta 42$ concentrations predicted a subsequent decline in MMSE scores between baseline and 24 months (Fig. $4 A$ ). In the AD/MCI model, $\mathrm{A} \beta$ burden at both baseline and month 24 , and higher CSF p-tau concentrations at month 24 (trending also at baseline; $p=0.07$ ), predicted subsequent MMSE scores (Fig. 4B). The complete covariance and correlation matrices are provided in Fig. 4-1, available at https://doi.org/10.1523/JNEUROSCI.1056-19.2019.f4-1, Fig. 4-2, available at https://doi.org/10.1523/JNEUROSCI.105619.2019.f4-2, Fig. 4-3, available at https://doi.org/10.1523/ JNEUROSCI.1056-19.2019.f4-3, and Fig. 4-4, available at https:// doi.org/10.1523/JNEUROSCI.1056-19.2019.f4-4, and the results are summarized in Table 2.

\section{Discussion}

In healthy elderly and in patients with $\mathrm{AD}$ or MCI, CSF and PET $\mathrm{A} \beta$ biomarkers demonstrated reciprocal predictive relationships, 

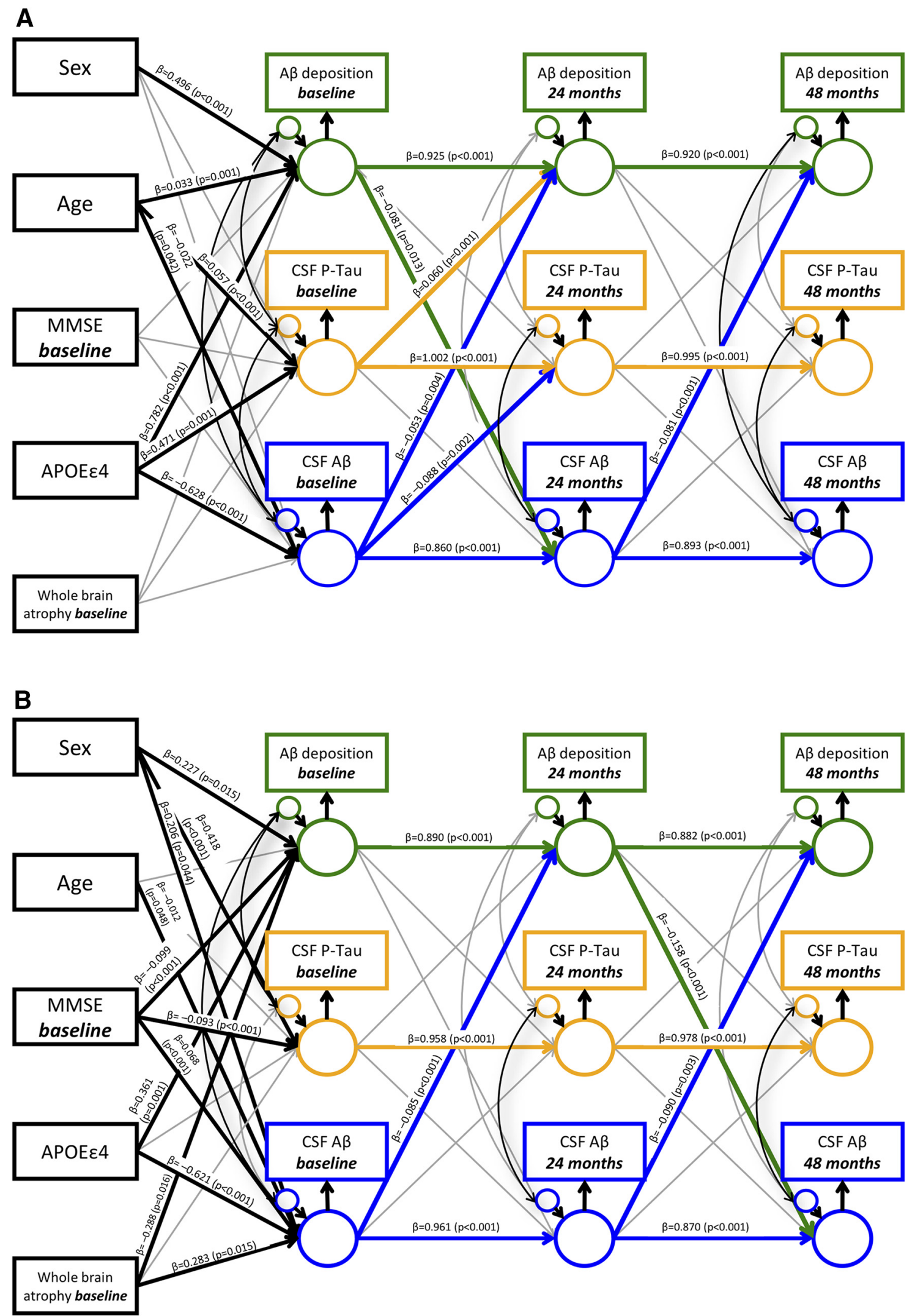

Figure 2. Cross-lagged panel model results in ( $\boldsymbol{A}$ ) HC and (B) AD/MCl subjects. PET-derived A $\beta$ burden, CSF p-tau concentrations, and CSF A $\beta 42$ concentrations are modeled across three waves (baseline, 24 months, and 48 months) with covariates sex, baseline age, baseline MMSE score, APOE $\varepsilon 4$, and baseline whole-brain atrophy. Rectangles, Observed variables; large circles, grand mean centered variables; small circles, residual variances; thin gray arrows, nonsignificant longitudinal predictions or correlations between residuals; black arrows, significant covariate associations or correlations between residuals; green arrows, significant longitudinal predictions from $A \beta$ deposition to a variable at a subsequent time point; orange arrows, significant longitudinal predictions from CSF p-tau concentrations to a variable at a subsequent time point; blue arrows, significant longitudinal predictions from CSF A $\beta$ concentrations to a variable at a subsequent time point. Standardized coefficients $(\beta)$ and $p$ values are displayed for all significant predictions. The complete covariance and correlation matrices are provided for $\mathrm{HC}$ in (Figure legend continues.) 


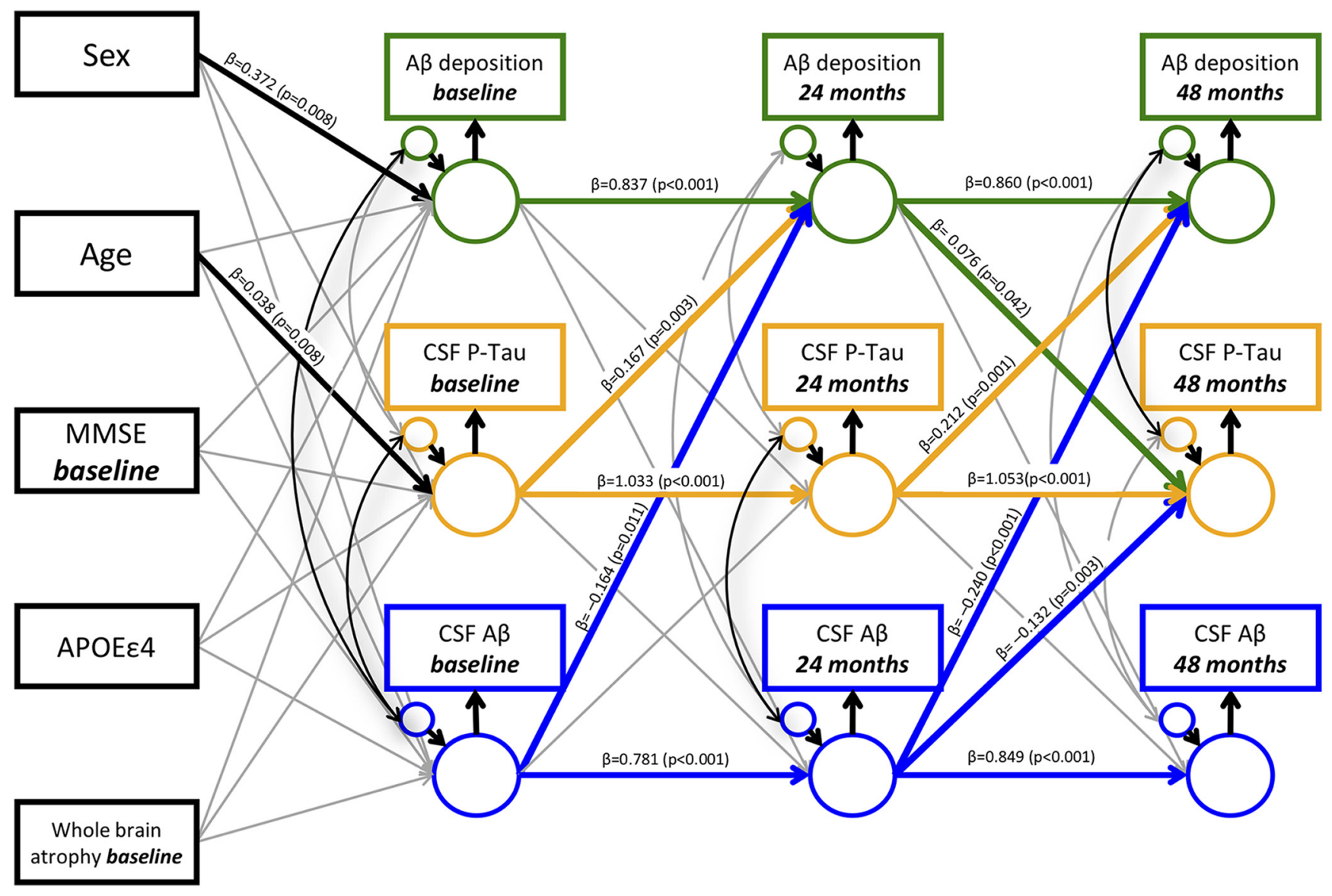

Figure 3. Cross-lagged panel model results in a subgroup of HC subjects who are A $\beta$-.PET-derived A $\beta$ burden, CSF $p$-tau concentrations, and CSF A $\beta 42$ concentrations are modeled across three waves (baseline, 24 months, and 48 months) with covariates sex, baseline age, baseline MMSE score, APOE $\varepsilon 4$, and baseline whole-brain atrophy. The complete covariance and correlation matrices are provided in Figure 3-1 (available at https://doi.org/10.1523/JNEUROSCI.1056-19.2019.f3-1) and Figure 3-2 (available at https://doi.org/10.1523/JNEUROSCI.1056-19.2019.f3-2). Figure legend as described in Figure 2.

consistent with an amyloid cascade model. Although CSF and PET A $\beta$ biomarkers track the same protein, they relay some unique information about the processes underlying $\mathrm{AD}$ pathogenesis (Mattsson et al., 2015). Previous observations suggest that CSF and PET A $\beta$ biomarkers detect different forms of the protein (i.e., soluble $A \beta 42$ vs extracellular fibrillar $A \beta$ ), and that CSF $\mathrm{A} \beta 42$ changes stage earlier in $\mathrm{AD}$ progression (Fagan et al., 2009; Jack et al., 2013), consistent with the finding that CSF A $\beta 42$ concentrations consistently predicted subsequent $A \beta$ deposition in the present models. Reciprocally, the PET A $\beta$ signal also predicted CSF A $\beta 42$ changes, although this direction of prediction was observed only in the HC group that included PET A $\beta+$ people and in $\mathrm{AD} / \mathrm{MCI}$, suggesting that appreciable amyloid burden might be required before the PET A $\beta$ signal predicts subsequent CSF A $\beta 42$ changes. Some have attributed this to differences in biomarker sensitivity (Palmqvist et al., 2016; Schindler et al., 2018); however, recent findings argue that even subthreshold amyloid PET measures are meaningful in asymptomatic people

$\leftarrow$

(Figure legend continued.) Figure 2-1 (available at https://doi.org/10.1523/JNEUROSCl. 1056-19.2019.f2-1) and Figure 2-2 (available at https://doi.org/10.1523/JNEUROSCl.105619.2019.f2-2), and for AD/MCl in Figure 2-3 (available at https://doi.org/10.1523/ JNEUROSCI.1056-19.2019.f2-3) and Figure 2-4 (available at https://doi.org/10.1523/ JNEUROSCI.1056-19.2019.f2-4). as they can predict tau accumulation and cognitive decline (Leal et al., 2018; Hanseeuw et al., 2019).

The specific mechanisms underlying the drop in CSF A $\beta 42$ remain unclear. It has been suggested that the drop in CSF A $\beta$ might be caused by its deposition in fibrillar/insoluble form (Motter et al., 1995; Fagan et al., 2006). In that case, the empirical model might be expected to show the PET signal to predict CSF changes more consistently. Impaired efflux or trapping of $A \beta$ in the interstitial fluid (e.g., in oligomeric form) could also prevent movement into the CSF. If the radiotracer failed to detect oligomeric species in interstitial fluid, then a drop in CSF A $\beta 42$ concentrations might be expected to predict changes in the PET A $\beta$ signal. The initial change in CSF A $\beta 42$ concentrations has also been suggested to involve defects in $\mathrm{A} \beta$ processing and/or intraneuronal transport related to accumulation in autophagic vesicles (possibly because of cell stress and dysfunction of the endosomal-lysosomal system), which has been shown to occur early in $\mathrm{AD}$ pathogenesis and to precede extracellular deposition around dystrophic neurites (Nixon, 2007).

In healthy elderly some evidence of a reciprocally predictive relationship between $A \beta$ and tau biomarker progression was seen; lower CSF A $\beta 42$ concentrations variably predicted subsequent increases in CSF p-tau, CSF p-tau variably predicted $A \beta$ deposition, and $\mathrm{A} \beta$ deposition variably predicted subsequent increases in CSF p-tau. The results are consistent with animal studies suggesting that tau and $\mathrm{A} \beta$ can have co-propagating activities. 

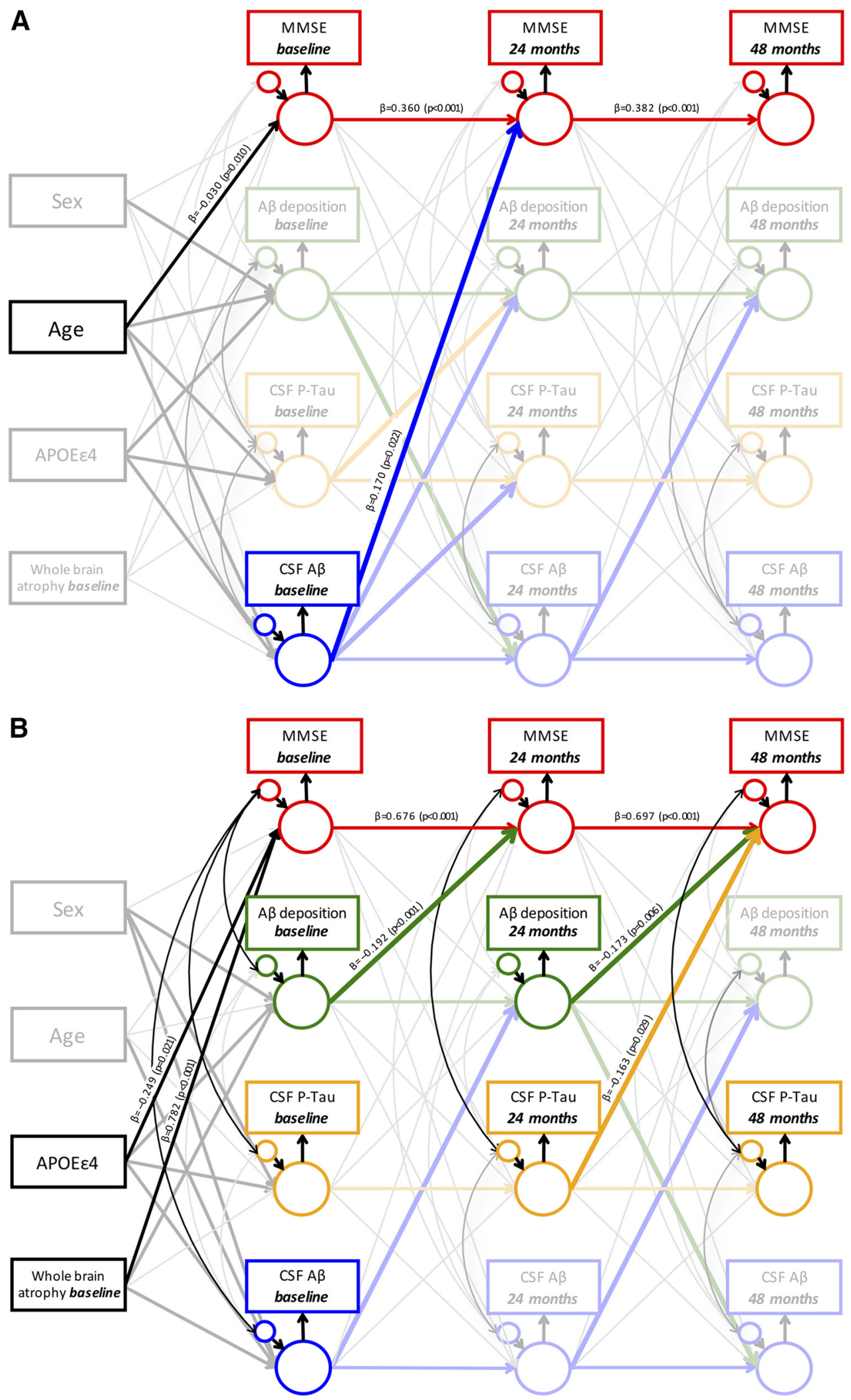

Figure 4. Posthoc cross-lagged panel model results with longitudinal MMSE scores in $(\boldsymbol{A}) \mathrm{HC}$ and $(\boldsymbol{B}) \mathrm{AD} / \mathrm{MCl}$ subjects. PET-derived A $\beta$ burden, CSF p-tau concentration, CSF A $\beta 42$ concentrations, and MMSE scores are modeled across three waves (baseline, 24 months, and 48 months) with covariates sex, baseline age, APOE $\varepsilon 4$, and baseline whole-brain atrophy. Legend as in Figure 2. Standardized coefficients $(\beta)$ and $p$ values are displayed for all significant longitudinal predictions between MMSE scores and other cross-lagged variables, and for all significant associations between baseline covariates and MMSE scores. The complete covariance and correlation matrices are provided for HC in Figure 4-1 (available at https://doi.org/10.1523/JNEUROSCI.105619.2019.f4-1), and in Figure 4-2 (available at https://doi.org/10.1523/JNEUROSCl.1056-19.2019.f4-2), and for AD/MCI in Figure 4-3 (available at https://doi.org/10.1523/JNEUROSCI.105619.2019.f4-3) and Figure 4-4 (available at https://doi.org/10.1523/JNEUROSCI.1056-19.2019.f4-4). 
Table 2. Summary of findings in healthy elderly and AD/MCI groups

\begin{tabular}{|c|c|c|}
\hline & Longitudinal predictive results & Cross-sectional correlations \\
\hline Healthy elderly & $\begin{array}{l}\text { - Lower CSF } A \beta 42 \text { predicted increased } A \beta \text { deposition } \\
\text { - Greater } A \beta \text { burden variably predicted lower CSF } A \beta 42 \text { (not in the } A \beta \text { - subgroup) } \\
\text { - Lower CSF } A \beta 42 \text { predicted increased CSF p-tau } \\
\text { - Higher CSF p-tau predicted increased A } \beta \text { deposition } \\
\text { - Lower CSF } A \beta 42 \text { variably predicted lower MMSE scores }\end{array}$ & $\begin{array}{l}\text { - Negative correlation between CSF A } \beta 42 \text { and } A \beta \text { burden } \\
\text { - Positive correlation between CSF p-tau and A } \beta \text { burden } \\
\text { - Positive correlation between CSF A } \beta 42 \text { and CSF p-tau (the } A \beta \text { - subgroup only) } \\
\text { - Negative correlation between } A \beta \text { burden and MMSE scores at } 48 \text { months }\end{array}$ \\
\hline $\mathrm{AD} / \mathrm{MCl}$ & $\begin{array}{l}\text { - Lower CSF A } \beta 42 \text { predicted increased A } \beta \text { deposition } \\
\text { - Greater } A \beta \text { burden predicted lower CSF } A \beta 42 \\
\text { - Greater } A \beta \text { burden predicted lower MMSE scores } \\
\text { - Higher CSF p-tau concentrations variably predicted lower MMSE scores }\end{array}$ & $\begin{array}{l}\text { - Negative correlation between CSF A } \beta 42 \text { and A } \beta \text { burden } \\
\text { - Positive correlation between CSF p-tau and A } \beta \text { burden } \\
\text { - Positive correlation between CSF A } \beta 42 \text { and MMSE scores } \\
\text { - Negative correlation between CSF p-tau and MMSE scores } \\
\text { - Negative correlation between A } \beta \text { burden and MMSE scores }\end{array}$ \\
\hline
\end{tabular}

In animals, $A \beta$ increases tau hyperphosphorylation and NFT formation (Stancu et al., 2014). Reciprocally, overexpression of human tau in APP transgenic mice can increase $A \beta$ deposition (Bright et al., 2015; Jackson et al., 2016), tau immunization can reduce $\mathrm{A} \beta$ plaque burden (Dai et al., 2017), and exogenous extracellular tau can increase $\mathrm{A} \beta$ production in vitro (Bright et al., 2015). Those studies suggest that interactions between $A \beta$ and tau might be cyclic in nature. In the present models, CSF p-tau specifically predicted $A \beta$ deposition, and reciprocally, there was some evidence that $\mathrm{A} \beta$ deposition could predict CSF $\mathrm{p}$-tau progression. In cross-sectional correlations, CSF p-tau concentrations were correlated with $\mathrm{A} \beta$ burden but not with CSF A $\beta 42$ concentrations, as previously reported (Mattsson et al., 2015); however, CSF A $\beta 42$ concentrations were positively correlated with CSF p-tau uniquely in the subgroup of $A \beta-\mathrm{HC}$, suggesting that in the absence of Alzheimer's disease, these markers may have different relationships.

Because of uncertainties in the neurobiological underpinnings of the biomarkers and a lack of definitive causal inferences, the implications of the present model for preventative interventions are unclear. In HC, lower CSF A $\beta 42$ variably predicted changes in cognitive status, so it might be speculated that identifying and targeting the mechanism(s) underlying this biomarker might prevent early changes in cognitive status due to $\mathrm{AD}$ in healthy elderly people. The prediction of $\mathrm{A} \beta$ deposition by CSF p-tau seen in HC might also suggest that strategies targeting tau, either directly or indirectly via other processes that lead to tau accrual (Kim et al., 2018; Rabin et al., 2019; e.g., cerebral small vessel disease, vascular risk factors, diabetes, head trauma, etc.), might slow amyloid deposition in asymptomatic people. In a recent study, healthy elderly people with both amyloid and tau PET accrual showed greater memory decline (Sperling et al., 2019); however, CSF A $\beta 42$ was not examined, which based on the present results might be hypothesized to predict both $\mathrm{A} \beta$ and tau PET signals. Further prospective studies of asymptomatic/presymptomatic people will be needed to determine how the interplay between CSF and PET biomarkers predicts the development of clinical AD.

In $\mathrm{AD} / \mathrm{MCI}$, there was no evidence to support reciprocal predictions between $A \beta$ and tau biomarkers. The reason for this is unclear. One possibility is that the biomarkers reached plateaus before these symptomatic stages. It has been suggested that CSF A $\beta 42$ concentrations tend to bottom-out before the onset of symptoms (Buchhave et al., 2012), and that $\mathrm{A} \beta$ deposition might also plateau earlier in disease progression than once thought (Leal et al., 2018). The empirical model suggests that this may not entirely account for the null findings because the amyloid biomarkers continued to exhibit dynamic interplay in $\mathrm{AD} / \mathrm{MCI}$, each predicting progression of the other. Therefore, it is possible that amyloid and tau biomarkers progressed independently of one another in AD/MCI. It has been suggested that extracellular p-tau can spread between neurons independently of amyloid, possibly driving neuronal hyperexcitability and disease progression in symptomatic stages (Bright et al., 2015; Goedert and Spillantini, 2017). Consistent with those hypotheses, here CSF p-tau concentrations variably predicted cognitive decline in AD/MCI.

The lack of predictive relationships between tau and amyloid in $\mathrm{AD} / \mathrm{MCI}$ might have therapeutic implications. Recent studies using PET-derived tau measures suggest that tau deposition mediates the relationship between $\mathrm{A} \beta$ burden and cognitive status (Kim et al., 2018; Hanseeuw et al., 2019), consistent with autopsy studies that showed closer correlations between cognitive status and tangles than plaques (Arriagada et al., 1992; Giannakopoulos et al., 2003). If tau progresses independently of amyloid deposition once $\mathrm{AD} / \mathrm{MCI}$ is established, then therapies targeting extracellular amyloid may be insufficient to halt cognitive progression. In the present study, both $\mathrm{A} \beta$ burden and CSF $\mathrm{p}$-tau predicted cognitive decline independently, and if true, targeting their distinct underlying molecular processes simultaneously may be necessary to halt disease progression. This would be consistent with the failure of amyloid-targeted monotherapies in AD clinical trials to date (Mehta et al., 2017). Moreover, examining CSF biomarkers together with the PET A $\beta$ signal over time revealed that CSF $\mathrm{A} \beta 42$ concentrations consistently predicted $\mathrm{A} \beta$ deposition in $\mathrm{AD} / \mathrm{MCI}$, suggesting that mechanisms underlying the drop CSF $A \beta 42$ were sustained throughout $\mathrm{AD}$ progression. It might be speculated that targeting those mechanisms, which may include but may not be limited to $A \beta$ deposition, might be of therapeutic benefit in symptomatic stages.

This study has several limitations. As an empirical approach, the CLPM offers the advantage of making the cascade hypothesis explicitly testable; however, causality cannot be inferred explicitly, and the model is data-demanding leading to sample-size limitations; not all identified cross-lagged predictions reached significance consistently between the two lag periods, and there were insufficient data to construct the models in the subgroup of PET A $\beta+\mathrm{HC}$, an important limitation to be addressed in future studies. Because a similar independent dataset was unavailable, replication was not possible. Additional waves would be required to model explicitly interindividual differences as trait-like features, although subgroup analyses accounted meaningfully for population heterogeneity (Hamaker et al., 2015). Too few longitudinal AV-1451 PET measures were available to model in ADNI cohorts, precluding exploration of tau deposition dynamics and regional specificity in brain; however, CSF p-tau appears to correlate with tau deposition (Brier et al., 2016), making CSF p-tau a reasonable proxy of pathologic tau for the present objectives. We propose further applications of the model to establish how the 
present findings link with biomarkers of neurodegeneration, and to identify pathophysiological processes that predict decreases in CSF A $\beta 42$ as potential targets for prevention and treatment.

In conclusion, to our knowledge, this is the first empirical model to test reciprocal predictive relationships between amyloid and tau biomarkers as they progressed over time in living people. The empirical biomarker model is consistent with a hypothetical amyloid cascade involving reciprocal predictions between amyloid and tau progression in healthy elderly people, wherein tau specifically predicted amyloid deposition but not CSF A $\beta 42$ changes. In healthy elderly people, lower CSF A $\beta 42$ concentrations predicted subsequent amyloid deposition and CSF p-tau changes, consistent with the proposed staging of these biomarkers (Jack et al., 2013), and a decline in cognitive status. The empirical model further suggested that amyloid and tau biomarkers progressed independently in people with established AD/MCI. In $\mathrm{AD} / \mathrm{MCI}, \mathrm{CSF} \mathrm{A} \beta 42$ concentrations predicted $\mathrm{A} \beta$ deposition, which predicted cognitive decline, and CSF p-tau concentrations predicted cognitive decline independently. The results provide clarification regarding the dynamics of $\mathrm{AD}$ biomarker progression and its relationships with cognitive decline, consistent with priorities identified by The National Institute on Aging-Alzheimer's Association updated research framework (Jack et al., 2018).

\section{References}

Arriagada PV, Growdon JH, Hedley-Whyte ET, Hyman BT (1992) Neurofibrillary tangles but not senile plaques parallel duration and severity of Alzheimer's disease. Neurology 42:631-639.

Blennow K, Mattsson N, Schöll M, Hansson O, Zetterberg H (2015) Amyloid biomarkers in Alzheimer's disease. Trends Pharmacol Sci 36: 297-309.

Braak H, Braak E (1997) Frequency of stages of Alzheimer-related lesions in different age categories. Neurobiol Aging 18:351-357.

Brier MR, Gordon B, Friedrichsen K, McCarthy J, Stern A, Christensen J, Owen C, Aldea P, Su Y, Hassenstab J, Cairns NJ, Holtzman DM, Fagan AM, Morris JC, Benzinger TL, Ances BM (2016) Tau and A $\beta$ imaging, CSF measures, and cognition in Alzheimer's disease. Sci Transl Med 8:338ra66

Bright J, Hussain S, Dang V, Wright S, Cooper B, Byun T, Ramos C, Singh A, Parry G, Stagliano N, Griswold-Prenner I (2015) Human secreted tau increases amyloid-beta production. Neurobiol Aging 36:693-709.

Buchhave P, Minthon L, Zetterberg H, Wallin AK, Blennow K, Hansson O (2012) Cerebrospinal fluid levels of $\beta$-amyloid $1-42$, but not of tau, are fully changed already 5 to 10 years before the onset of Alzheimer dementia. Arch Gen Psychiatry 69:98-106.

Castello MA, Jeppson JD, Soriano S (2014) Moving beyond anti-amyloid therapy for the prevention and treatment of Alzheimer's disease. BMC Neurol 14:169.

Cho H, Lee HS, Choi JY, Lee JH, Ryu YH, Lee MS, Lyoo CH (2018) Predicted sequence of cortical tau and amyloid- $\beta$ deposition in alzheimer disease spectrum. Neurobiol Aging 68:76-84.

Dai CL, Tung YC, Liu F, Gong CX, Iqbal K (2017) Tau passive immunization inhibits not only tau but also $\mathrm{A} \beta$ pathology. Alzheimers Res Ther 9:1.

Fagan AM, Mintun MA, Mach RH, Lee SY, Dence CS, Shah AR, LaRossa GN, Spinner ML, Klunk WE, Mathis CA, DeKosky ST, Morris JC, Holtzman DM (2006) Inverse relation between in vivo amyloid imaging load and cerebrospinal fluid $\mathrm{A} \beta_{42}$ in humans. Ann Neurol 59:512-519.

Fagan AM, Mintun MA, Shah AR, Aldea P, Roe CM, Mach RH, Marcus D, Morris JC, Holtzman DM (2009) Cerebrospinal fluid tau and ptaul 181 increase with cortical amyloid deposition in cognitively normal individuals: implications for future clinical trials of Alzheimer's disease. EMBO Mol Med 1:371-380.

Giannakopoulos P, Herrmann FR, Bussière T, Bouras C, Kövari E, Perl DP, Morrison JH, Gold G, Hof PR (2003) Tangle and neuron numbers, but not amyloid load, predict cognitive status in Alzheimer's disease. Neurology 60:1495-1500.

Goate A, Chartier-Harlin MC, Mullan M, Brown J, Crawford F, Fidani L, Giuffra L, Haynes A, Irving N, James L, Mant R, Newton P, Rooke K, Roques P, Talbot C, Pericak-Vance M, Roses A, Williamson R, Rossor M,
Owen M, Hardy J (1991) Segregation of a missense mutation in the amyloid precursor protein gene with familial Alzheimer's disease. Nature 349:704-706.

Goedert M, Spillantini MG (2017) Propagation of tau aggregates. Mol Brain 10:18.

Hamaker EL, Kuiper RM, Grasman RP (2015) A critique of the cross-lagged panel model. Psychol Methods 20:102-116.

Hanseeuw, Betensky RA, Jacobs HIL, Schultz AP, Sepulcre J, Becker JA, Cosio DM, Farrell M, Quiroz YT, Mormino EC, Buckley RF, Papp KV, Amariglio RA, Dewachter I, Ivanoiu A, Huijbers W, Hedden T, Marshall GA, Chhatwal JP, Rentz DM, Sperling RA, Johnson K, et al. (2019) Association of amyloid and tau with cognition in preclinical Alzheimer disease: a longitudinal study. JAMA Neurol. Advance online publication. Retrieved June 19, 2019. doi:10.1001/jamaneurol.2019.1424.

Hardy J, Selkoe DJ (2002) The amyloid hypothesis of Alzheimer's disease: progress and problems on the road to therapeutics. Science 297:353-356.

Hutton M, Lendon CL, Rizzu P, Baker M, Froelich S, Houlden H, PickeringBrown S, Chakraverty S, Isaacs A, Grover A, Hackett J, Adamson J, Lincoln S, Dickson D, Davies P, Petersen RC, Stevens M, de Graaff E, Wauters E, van Baren J, et al. (1998) Association of missense and 5'-splice-site mutations in tau with the inherited dementia FTDP-17. Nature 393: 702-705.

Ittner LM, Götz J (2011) Amyloid- $\beta$ and tau: a toxic pas de deux in Alzheimer's disease. Nat Rev Neurosci 12:65-72.

Jack CR Jr, Knopman DS, Jagust WJ, Petersen RC, Weiner MW, Aisen PA, Shaw LM, Vemuri P, Wiste HJ, Weigand SD, Lesnick TG, Pankratz VS, Donohue MC, Trojanowski JQ (2013) Update on hypothetical model of Alzheimer's disease biomarkers. Lancet Neurol 12:207-216.

Jack CR Jr, Bennett DA, Blennow K, Carrillo MC, Dunn B, Haeberlein SB, Holtzman DM, Jagust W, Jessen F, Karlawish J, Liu E, Molinuevo JL, Montine T, Phelps C, Rankin KP, Rowe CC, Scheltens P, Siemers E, Snyder HM, Sperling R (2018) NIA-AA research framework: toward a biological definition of Alzheimer's disease. Alzheimers Dement 14:535-562.

Jackson RJ, Rudinskiy N, Herrmann AG, Croft S, Kim JM, Petrova V, RamosRodriguez JJ, Pitstick R, Wegmann S, Garcia-Alloza M, Carlson GA, Hyman BT, Spires-Jones TL (2016) Human tau increases amyloid $\beta$ plaque size but not amyloid $\beta$-mediated synapse loss in a novel mouse model of Alzheimer's disease. Eur J Neurosci 44:3056-3066.

Johnson KA, Sperling RA, Gidicsin CM, Carmasin JS, Maye JE, Coleman RE, Reiman EM, Sabbagh MN, Sadowsky CH, Fleisher AS, Murali Doraiswamy P, Carpenter AP, Clark CM, Joshi AD, Lu M, Grundman M, Mintun MA, Pontecorvo MJ, Skovronsky DM (2013) Florbetapir (F18AV-45) PET to assess amyloid burden in Alzheimer's disease dementia, mild cognitive impairment, and normal aging. Alzheimers Dement 9:S72-S83.

Karran E, Mercken M, De Strooper B (2011) The amyloid cascade hypothesis for Alzheimer's disease: an appraisal for the development of therapeutics. Nat Rev Drug Discov 10:698-712.

Kenny DA, Harackiewicz JM (1979) Cross-lagged panel correlation: practice and promise. J Appl Psychol 64:372-379.

Kim HJ, Park S, Cho H, Jang YK, San Lee J, Jang H, Kim Y, Kim KW, Ryu YH, Choi JY, Moon SH, Weiner MW, Jagust WJ, Rabinovici GD, DeCarli C, Lyoo CH, Na DL, Seo SW (2018) Assessment of extent and role of tau in subcortical vascular cognitive impairment using $18 \mathrm{~F}-\mathrm{AV} 1451$ positron emission tomography imaging. JAMA Neurol 75:999-1007.

Landau SM, Fero A, Baker SL, Koeppe R, Mintun M, Chen K, Reiman EM, Jagust WJ (2015) Measurement of longitudinal $\beta$-amyloid change with ${ }^{18} \mathrm{~F}$-florbetapir PET and standardized uptake value ratios. J Nucl Med 56:567-574.

Leal SL, Lockhart SN, Maass A, Bell RK, Jagust WJ (2018) Subthreshold amyloid predicts tau deposition in aging. J Neurosci 38:4482-4489.

Levy-Lahad E, Wasco W, Poorkaj P, Romano DM, Oshima J, Pettingell WH, Yu CE, Jondro PD, Schmidt SD, Wang K, Crowley AC, Fu YH, Guenette SY, Galas D, Nemens E, Wijsman EM, Bird TD, Schellenberg GD, Tanzi RE (1995) Candidate gene for the chromosome 1 familial Alzheimer's disease locus. Science 269:973-977.

Mattsson N, Insel PS, Donohue M, Landau S, Jagust WJ, Shaw LM, Trojanowski JQ, Zetterberg H, Blennow K, Weiner MW (2015) Independent information from cerebrospinal fluid amyloid- $\beta$ and florbetapir imaging in Alzheimer's disease. Brain 138:772-783.

Mehta D, Jackson R, Paul G, Shi J, Sabbagh M (2017) Why do trials for 
Alzheimer's disease drugs keep failing? A discontinued drug perspective for 2010-2015. Expert Opin Investig Drugs 26:735-739.

Motter R, Vigo-Pelfrey C, Kholodenko D, Barbour R, Johnson-Wood K, Galasko D, Chang L, Miller B, Clark C, Green R, Olson D, Southwick P, Wolfert R, Munroe B, Lieberburg I, Seubert P, Schenk D (1995) Reduction of $\beta$-amyloid peptide 42 in the cerebrospinal fluid of patients with Alzheimer's disease. Ann Neurol 38:643-648.

Nixon RA (2007) Autophagy, amyloidogenesis and Alzheimer disease. J Cell Sci 120:4081-4091.

Palmqvist S, Mattsson N, Hansson O (2016) Cerebrospinal fluid analysis detects cerebral amyloid- $\beta$ accumulation earlier than positron emission tomography. Brain 139:1226-1236.

Rabin JS, Yang HS, Schultz AP, Hanseeuw BJ, Hedden T, Viswanathan A, Gatchel JR, Marshall GA, Kilpatrick E, Klein H, Rao V, Buckley RF, Yau WW, Kirn DR, Rentz DM, Johnson KA, Sperling RA, Chhatwal JP (2019) Vascular risk and $\beta$-amyloid are synergistically associated with cortical tau. Ann Neurol 85:272-279.

Schindler SE, Gray JD, Gordon BA, Xiong C, Batrla-Utermann R, Quan M, Wahl S, Benzinger TLS, Holtzman DM, Morris JC, Fagan AM (2018) Cerebrospinal fluid biomarkers measured by Elecsys assays compared to amyloid imaging. Alzheimers Dement 14:1460-1469.

Schraen-Maschke S, Sergeant N, Dhaenens CM, Bombois S, Deramecourt V, Caillet-Boudin ML, Pasquier F, Maurage CA, Sablonnière B, Van- mechelen E, Buée L (2008) Tau as a biomarker of neurodegenerative diseases. Biomark Med 2:363-384.

Sherrington R, Rogaev EI, Liang Y, Rogaeva EA, Levesque G, Ikeda M, Chi H, Lin C, Li G, Holman K, Tsuda T, Mar L, Foncin JF, Bruni AC, Montesi MP, Sorbi S, Rainero I, Pinessi L, Nee L, Chumakov I, et al. (1995) Cloning of a gene bearing missense mutations in early-onset familial Alzheimer's disease. Nature 375:754-760.

Small SA, Duff K (2008) Linking A $\beta$ and tau in late-onset Alzheimer's disease: a dual pathway hypothesis. Neuron 60:534-542.

Sperling RA, Mormino EC, Schultz AP, Betensky RA, Papp KV, Amariglio RE, Hanseeuw BJ, Buckley R, Chhatwal J, Hedden T, Marshall GA, Quiroz YT, Donovan NJ, Jackson J, Gatchel JR, Rabin JS, Jacobs H, Yang HS, Properzi M, Kirn DR, et al. (2019) The impact of amyloid-beta and tau on prospective cognitive decline in older individuals. Ann Neurol $85: 181-193$

Stancu IC, Vasconcelos B, Terwel D, Dewachter I (2014) Models of betaamyloid induced tau-pathology: the long and "folded" road to understand the mechanism. Mol Neurodegener 9:51.

Tapiola T, Alafuzoff I, Herukka SK, Parkkinen L, Hartikainen P, Soininen H, Pirttilä T (2009) Cerebrospinal fluid $\beta$-amyloid 42 and tau proteins as biomarkers of Alzheimer-type pathologic changes in the brain. Arch Neurol 66:382-389. 